\title{
A Fractal Prediction Method for Safety Monitoring Deformation of Core Rockfill Dams
}

\author{
Liang Pei $\mathbb{D}^{1}$, ${ }^{1,2}$ Jiankang Chen $\mathbb{D}^{1},{ }^{1,2}$ Jingren Zhou $\mathbb{D}^{1,2}$ Huibao Huang, ${ }^{3}$ Zhengjun Zhou, ${ }^{4}$ \\ Chen Chen, ${ }^{1,2}$ and Fuhai Yao ${ }^{3}$
}

${ }^{1}$ State Key Lab. of Hydraulics and Mountain River Eng, Sichuan University, Chengdu 610065, China

${ }^{2}$ College of Water Resource \& Hydropower, Sichuan University, Chengdu 610065, China

${ }^{3}$ Dadu River Hydropower Development Corporation Limited, Chengdu 610016, China

${ }^{4}$ Powerchina Chengdu Engineering Corporation Limited, Chengdu 610072, China

Correspondence should be addressed to Jingren Zhou; zhoujingrenscu@scu.edu.cn

Received 14 October 2020; Revised 31 December 2020; Accepted 11 January 2021; Published 21 January 2021

Academic Editor: Francesc Pozo

Copyright (C) 2021 Liang Pei et al. This is an open access article distributed under the Creative Commons Attribution License, which permits unrestricted use, distribution, and reproduction in any medium, provided the original work is properly cited.

Deformation mechanism in the core rockfill dams with heavy load and high-stress level is difficult to predict and control, which is one of the key problems to be solved in the dam operation safety management and control. Aiming at the large error problems obtained by the parameter-based functional models (regression model, grey theory model, etc.) in the deformation prediction of the core rockfill dams, a fractal prediction method and its technical process by combining the variable dimension fractal dimension and the "metabolism" of prediction data are proposed through analyzing the fractal adaptability and deformation characteristics of original monitoring data based on the resealed-range $(\mathrm{R} / \mathrm{S})$ method and fractal dimension theory. It effectively solves the error in the process of constant dimension fractal accumulation and transformation greatly in dam deformation prediction and provides a new way for dam safety monitoring deformation prediction and early warning. The trend analysis of deformation monitoring data of the Pubugou core rockfill dam and the deformation prediction show that the fractal prediction information of dam deformation has a good corresponding relationship with its physical causes, which is in line with the actual deformation trend and operation state of the dam. Compared with the traditional stepwise regression method, the prediction results obtained by the proposed method in this paper are of high accuracy, implying that the improved fractal prediction of dam deformation is effective and the Hurst fractal index is applicable in the evaluation of the dam deformation trend.

\section{Introduction}

Core rockfill dam plays an important role in the dam engineering field due to its good adaptability to the terrain and geological conditions, convenience for local materials, good seismic resistance, and other advantages [1], and most of the 200-300 m high Earth rockfill dams are core rockfill dams, such as the Nurek dam (300 m, Tajikistan), the Nuozhadu dam (261.5 m, China), the Mica dam (242 m, Canada), and Oroville dam (235 m, America). The deformation mechanism of a dam with complex topography, geology, operation environment, large loading in dam and foundation, and high-stress level is complex, and the deformation process and quantity value are closely related to dam safety.
Therefore, the deformation prediction and control is difficult and is one of the key scientific and technical problems to be solved in the construction and operation of rockfill dams [2-5].

In the aspect of dam deformation prediction analysis based on safety monitoring data, scholars have carried out fruitful work and some models have been promoted, mainly including the statistical model, grey theory model, and time series model [6-8]. Owing to the complex deformation mechanism, influencing factors, and strong nonlinear characteristics, many parameters are difficult to describe quantitatively, thereby leading to large errors by introducing the parameter-based functional models in deformation prediction. The fractal theory is an effective method to study 
nonlinear time series of data with the advantages of wide application range and strong robustness and has been applied to dam [9], slope [10], tunnel [11], mining [12], and other engineering deformation stability analysis. The fractal theory was used to describe the long-term behavior of dam structures through fractal exponents, and the diagnosis model and appropriate criterion for evolution characteristics of concrete dam crack are developed by combining the fractal, phase space reconstruction, and wavelet method $[13,14]$. Zhang et al. [15] put forward a fault analysis method based on the fractal characteristics of acoustic emission signals and assign it as an index to evaluate the overall safety of the dam. Wu et al. [16] proposed an improved fractal model to forecast mine slope deformation using the grey system theory. Hu et al. [17] concluded that the monitoring data curves of landslide monitoring points have fractal characteristics, and the fractal theory is of great significance to the prediction of landslide deformation trend, as well as for the monitoring data of dam crack [18]. Tu et al. [19] combined the fractal interpolation and ARIMA models to monitor dam safety. Additionally, the Hurst fractal index based on the time series and fractal dimensions are usually adopted to evaluate the state of projects with good effects [20-23]. However, there are still some deficiencies (e.g., error problems in the parameter-based functional models and error of constant dimension fractal accumulation and transformation) in the dynamic prediction of deformation in large-scale granular structures, especially the deformation prediction of a core rockfill dam.

This paper aims to study the prediction model of deformation in the core rockfill dams by improving the fractal methods. To achieve this, the main contents of the current research are arranged as follows: (a) based on fractional Brownian motion (FBM) test of dam deformation monitoring series, fractal adaptability of deformation monitoring series is discussed by combining the resealed-range $(\mathrm{R} / \mathrm{S})$ method and fractal dimension theory; (b) study the fractal dimension of deformation monitoring data series of core rockfill dam changing with time and then put forward the fractal prediction method and its technical process with the variable dimension fractal dimension and the "metabolism" of prediction data; (c) take the Pubugou core rockfill dam as an example, and the effectiveness of deformation prediction method and engineering applicability of Hurst fractal index in evaluating dam local deformation trend is verified.

\section{Methodology}

2.1. FBM Test of Dam Deformation Monitoring Series. The R/ $\mathrm{S}$ method is usually applied to judge whether the deformation monitoring data series meets long-range correlation. If the time series of dam deformation meets the meaning and logical theoretical requirements of R/S analysis, the Hurst fractal index of deformation monitoring data and its corresponding fractal information can be analyzed by the $\mathrm{R} / \mathrm{S}$ method to determine the development trend and stability of deformation, and then, the prediction of deformation can be made. The time series or its transformation form should obey fractional Brownian motion (FBM) when using the R/S method [24], and the method of the FBM test can be arranged as follows.

Assuming that the deformation time series of a point is $x^{(0)}=\left\{x^{0}(1), x^{0}(2), \ldots, x^{0}(n)\right\}$, a corresponding cumulative time series $x^{(1)}=\left\{x^{1}(1), x^{1}(2), \ldots, x^{1}(n)\right\}$ is given, which satisfies the following relationship:

$$
x^{1}(k)=\sum_{i=1}^{k} x^{0}(i) \text {. }
$$

If deformation time series $x^{(0)}$ is the nonnegative function, then $\alpha_{k}$ can be defined:

$$
\alpha_{k}=\frac{x^{(0)}(k)}{\sum_{1}^{k-1} x^{0}(i)}=\frac{x^{(0)}(k)}{x^{(1)}(k-1)} .
$$

If the deformation time series meets the FBM, it is certain that when $k>3, \alpha_{k}$ is the decreasing series and $0 \leq \alpha_{k} \leq 1$; when $n$ is big enough, the series of number converges to 0 .

\subsection{Deformation Characteristics Analysis of Core Rockfill Dam} Based on R/S Method. According to the R/S method, the fractal characteristics of the dam deformation monitoring series and its long-range correlation and trend strength can be judged by the Hurst fractal index of the nonlinear monitoring data of deformation.

The time series of deformation $x^{(0)}$ with a length of $N$ is divided into $m$ equal intervals of consecutive but not overlapping subintervals $A_{i}(i=1,2, \ldots, m)$ with a length of $n(2 \leq n \leq(N / 2))$, as shown in Figure 1. Each element in $A_{i}$ is $x_{i, k}(k=1,2, \ldots, N)$, and then, the average value $E_{i}$ of the series $A_{i}$ is

$$
E_{i}=\frac{1}{n} \sum_{k=1}^{n} x_{i, k}
$$

The standard deviation $S_{i}$ of series $A_{i}$, cumulative deviation $D_{i}$, and product moment $R_{i}$ can be calculated by the following equations:

$$
\begin{aligned}
S_{i} & =\sqrt{\frac{1}{n} \sum_{k=1}^{n}\left(x_{i, k}-E_{i}\right),} \\
D_{i} & =\sum_{k=1}^{n}\left(x_{i, k}-E_{i}\right), \\
R_{i} & =\max _{1 \leq k \leq n}\left(D_{i, k}\right)-\min _{1 \leq k \leq n}\left(D_{i, k}\right) .
\end{aligned}
$$
by

Also, the average $\left(R_{i} / S_{i}\right)$ of $m$ intervals can be expressed

$$
\left(\frac{R}{S}\right)_{n}=\frac{1}{m} \sum_{i=1}^{m} \frac{R_{i}}{S_{i}}
$$

According to the study of Mandelbrot et al. [25], the split length of data series $n$ and its $(R / S)_{n}$ satisfy the following relation: 


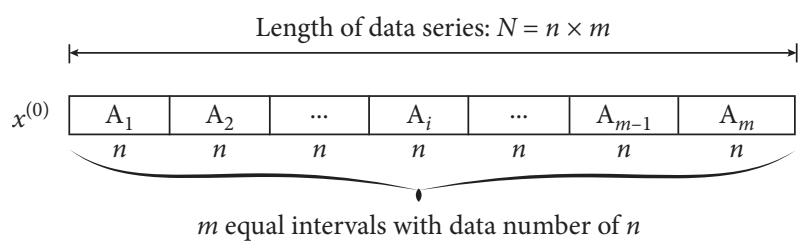

FIGURE 1: Schematic diagram of equal intervals.

$$
\lg \left(\frac{R}{S}\right)_{n}=\lg \theta+H \lg n
$$

where $\theta$ is a constant, showing the inherent characteristics of the time series system.

Taking $\lg n$ as the independent variable and $\lg (R / S)_{n}$ as the dependent variable, the slope of the fitting straight line is the Hurst fractal index of $\{x(t)\}$, which is the core parameter to describe the long-range correlation of time series.

As for the monitoring series of deformation in core rockfill dams, the Hurst fractal index $H$ is an indicator to measure the correlation and trend strength of the deformation time series with a range of $0 \sim 1$. The different levels of trend strength are concluded in Table 1 [26].

2.3. Improved Fractal Prediction Method. In the fractal theory, the fractal dimension $D$ is a generalization index used to describe the complexity of object shape, structure, and function, which can describe filling space extent of fractal geometry and information and reflect the complexity of function system [27, 28]. The meaning of fractal dimension analysis is that it can reflect the complexity and selfstability of a deformable system, and it can be adopted to describe the nonlinearity and disorder of dam deformation monitoring data series including the constant dimension fractal and variable dimension fractal.

The constant dimension fractal is usually expressed by the power exponential function as follows [29]:

$$
M=\frac{C}{r^{D}}
$$

where $r$ is the characteristic linearity, such as the length and time; $M$ is the physical quantity related to $r$, such as the temperature, stress, and deformation; $C$ is the parameter to be determined; and $D$ is a constant in constant dimension fractal.

As for a monitoring data series of deformation in the core rockfill dams, $r_{i}(i=1,2, \ldots, l)$ is defined according to the monitoring data, $l$ is the length of data series, and $M_{i}$ is defined as the value of deformation in the date of $r_{i}$. Therefore, the parameters of $D$ and $C$ can be expressed by any two points $\left(r_{i}, M_{i}\right)$ and $\left(r_{j}, M_{j}\right)$ just as follows:

$$
\begin{aligned}
& D=\frac{\ln \left(M_{i} / M_{j}\right)}{\ln \left(r_{j} / r_{i}\right)}, \\
& C=M_{i} r_{i}^{D} .
\end{aligned}
$$

In view that $D$ is a constant in constant dimension fractal, accumulation and transformation can be used for the variable dimension prediction and analysis, that is,

$$
\begin{aligned}
\left\{S_{1 i}\right\}= & \left\{M_{1}, M_{1}+M_{2}, M_{1}+M_{2}+M_{3}, \ldots\right\}, \\
\left\{S_{2 i}\right\}= & \left\{S_{11}, S_{11}+S_{12}, S_{11}+S_{12}+S_{13}, \ldots\right\}, \\
& \ldots \\
\left\{S_{j i}\right\}= & \left\{S_{(j-1) 1}, S_{(j-1) 1}+S_{(j-1) 2}, \ldots, S_{(j-1) 1}+S_{(j-1) 2}\right. \\
& \left.+S_{(j-1) 3}+\ldots+S_{(j-1) i}\right\}
\end{aligned}
$$

where $\left(S_{j i}\right)$ is the accumulation and series of the $j^{\text {th }}$ order.

After the accumulation and process of the original data series, the prediction value $M_{i}$ can be reversely obtained with a stable fractal dimension by the following equations:

$$
\begin{aligned}
S_{(j-1) i} & =S_{j i}-S_{j(i-1)}, \\
M_{i} & =S_{1 i}-S_{1(i-1)} .
\end{aligned}
$$

However, only a few monitoring data series in dams follow the law of constant dimension fractal, and more of them follow the variable dimension fractal. So the fractal dimension $D$ can be expressed as a function of characteristic linearity [25]:

$$
D=F(r)
$$

Then, the relation of series value $M$, fractal dimension $D$, and characteristic linearity $r$ can be given if $M$ and $r$ have a function relation of $M=f(r)$ :

$$
f(r)=\frac{C}{r^{F(r)}}
$$

Besides, the error of the original series obtained by the reverse inference will be larger if there is a prediction error in high order accumulation and series, so how to eliminate or reduce the error in reverse inference by adopting the accumulation and fractal to predict deformation is the key issue that must be solved. Typically, there are mainly two error sources in reverse inference during fractal dimension deformation prediction. On the one hand, there is a difference between the actual fractal dimension of the series and the fractal dimension selected in prediction. On the other hand, the acceptable absolute error amounts of each order accumulation and series are different due to the difference in the order of magnitudes. Therefore, the data close to the prediction point is selected to make the prediction, and the basic data of the former cycle used for prediction are constantly updated based on the "metabolism" principle according to the update cycle of monitoring data, thereby leading to the dynamic prediction of dam deformation.

As for the monitoring data series of deformation with complex nonlinearity in core rockfill dam, the monitoring data series shows the characteristic of long-range correlation within a certain time limit; otherwise, the series shows the uncorrelated random behavior and no self-similar feature. Therefore, a threshold time $T_{c}$ is assigned to describe the 
TABLE 1: Relation between the Hurst fractal index and the variation in deformation time series.

\begin{tabular}{lcccc}
\hline Range of $H$ & $(0,0.5)$ & 0.5 & $(0.5,1)$ & 1 \\
\hline Time series variation & Negative continuous effect & Random & Positive continuous effect & Fully certain \\
\hline
\end{tabular}

time limit of long-range correlation (Li et al., 2010), the known deformation data in threshold time limit can be used to make the deformation prediction based on the variable dimension fractal [30], and the key technical process of variable dimension fractal prediction of deformation in core rockfill dam is as follows:

(i) Step 1: relatively reliable basic data selection for the prediction. The randomness or certainty degree of deformation series and the long-range correlation characteristics of deformation are analyzed based on the R/S method, and the threshold time $T_{c}$ can be obtained by mutations point in the curve of $\lg n \sim \lg (R / S)_{n}$. It is noted that the initial time $T_{0}$ in the R/S method shall not be too small, and it is greater than the time corresponding to the series length greater than 10. For the core rockfill dams in this paper, $T_{0}$ is determined when the series length is 10 .

(ii) Step 2: prediction process. Firstly, a reasonable time scale $\Delta t$ within $\left(T_{0}, T_{c}\right)$ is determined, and the data belonging to the time are treated by the accumulation and transformation method (Equation (11)); the fractal parameters are determined based on the transformation with more stable dimension, and then, the reverse inference for the prediction can be made by Equations (12) (13).

(iii) It should be noted that the reasonable time scale $\Delta t$ within $\left(T_{0}, T_{c}\right)$ is very important, and it is related to the operation stage and the deformation behavior of the dams. Generally, the reasonable time scale can be about 3-6 months during the stable stage of deformation that changes periodically under the joint action of water level and temperature, or it can be about 1-3 months during the stage of impoundment or initial operation, in which the deformation of the dam is not completely stable.

(iv) Step 3: "metabolism" of the data series. The basic data used for prediction will be constantly updated based on actual monitoring frequency to reduce error produced from the accumulation and transformation of data series, and then, a relatively accurate real-time prediction of deformation series can be achieved, as seen in Figure 2.

Therefore, the flow chart for the prediction of deformation is given in Figure 3.

\section{Case Study}

3.1. Project Specifications. Pubugou core rockfill dam is the main hydraulic structure of Pubugou hydropower station whose installed capacity is 3.6 million KW on the Dadu
River. The hydropower station is mainly composed of three parts: a core rockfill dam, a water power generation system, and a discharge structure, with the layout shown in Figure 4. It is the highest core rockfill dam on the deep layers with a maximum dam height of $186 \mathrm{~m}$, a dam crest length of $540.5 \mathrm{~m}$, a dam crest width of $14 \mathrm{~m}$, and a dam bottom width of $96 \mathrm{~m}$. The elevation (EL) of the dam crest is $856.0 \mathrm{~m}$. The total filling quantity of the dam is 22.37 million $\mathrm{m}^{3}$. The largest thickness of the dam foundation overburden is $77.9 \mathrm{~m}$. The core takes two concrete diaphragm walls to reach enclosed impervious. The thickness of the concrete diaphragm wall is $1.2 \mathrm{~m}$. The distance between the center of the concrete diaphragm walls is $14 \mathrm{~m}$. The largest depth of the concrete diaphragm wall under the elevation of the bottom of the core is $82.9 \mathrm{~m}$.

The preconstruction of the Pubugou core rockfill dam began in March 2004. The river foundation treatment finished in April 2007, and the filling began. The dam filling finished in September 2009. The reservoir impoundment began on November 1, 2009. The impounded level reached the design elevation of $850 \mathrm{~m}$ on October 15, 2010. Figure 5 shows the layout of settlement points in section $0+240$, and points of VE1-20, VE1-21, and VE1-27 in the core area, LD59 in the dam crest, and $\mathrm{CH} 1 \sim \mathrm{CH} 4, \mathrm{CH} 5 \sim \mathrm{CH} 7$, and $\mathrm{CH} 10 \sim \mathrm{CH} 12$ in downstream rockfill area are adopted. The water level and temperature are shown in Figure 6. It is noted that the weather station in the Pubugou dam was built in May 2013, so the curve of temperature is given between May 2013 and April 2014.

\subsection{Fractal Adaptability Analysis of Dam Deformation} Monitoring Series. Deformation data series of three typical monitoring points in the core area, dam crest, and downstream rockfill area is selected to make the FBM test, in which the data series of settlement deformation in EL. $813.6 \mathrm{~m}$ of the core area (VE1-21), the horizontal deformation in the observation room of downstream rockfill area (EL. $758 \mathrm{~m}$ ), and settlement and horizontal deformation of dam crest (LD59) include the three stages of dam deformation, namely, construction filling, water storage, and normal operation. The FBM test results are shown in Figure 7.

As shown in Figure 7, $\alpha_{k}$ decreases with time with the range of $0 \sim 1$ when $k>3$, and the series converges to 0 when $n$ is big enough, implying that the deformation time series of the Pubugou core rockfill dam meets fractional Brownian motion. Additionally, the FBM tests of the deformation series in the Shiziping core rockfill dam are made for the R/S analysis, and the results show that the deformation series also meets the criteria of FBM. Therefore, it can be concluded that the deformation time series in core rockfill dams 


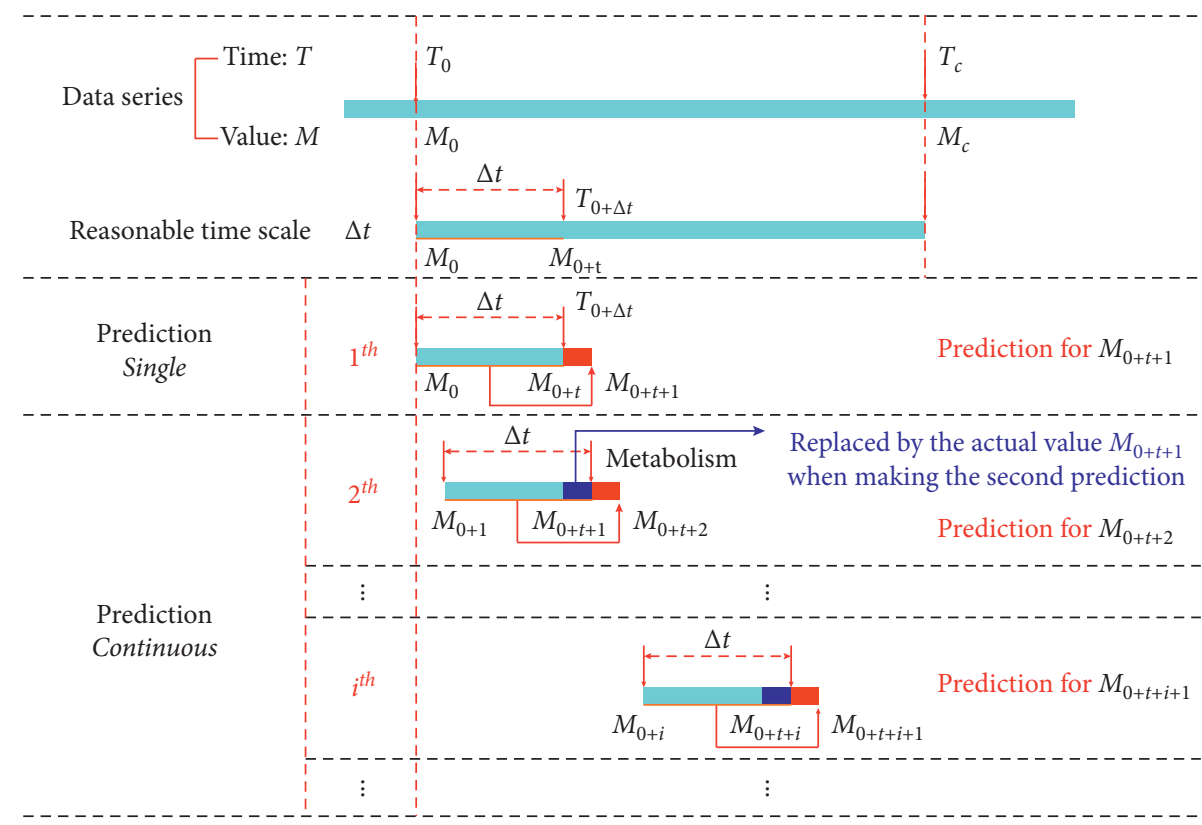

Figure 2: The "metabolism" for the prediction of data series in dams.

has significant fractal characteristics, and the R/S method can be used to study the fractional rule of dam deformation time series.

\subsection{Analysis of Deformation Trend}

3.3.1. Fractal Law of Deformation in Typical Monitoring Points of Dam. The deformation data series in section $0+240$ is selected as an example to analyze the trend and stability of deformation in the Pubugou core rockfill dam. Figure 8 shows the fractal index and the Hurst index of points VE1-20. As seen in Figure 8, the Hurst index is greater than 0.5 and becomes stable gradually with time. The fractal dimension of the deformation data series changes greatly in the first storage period, and the rest time is relatively stable, implying that the settlement deformation is stable.

Figures 9(a)-9(c) show the Hurst fractal index of settlement deformation in $\mathrm{CH} 1 \sim \mathrm{CH} 7$ and $\mathrm{CH} 10 \sim \mathrm{CH} 12$. It can be seen that the maximum and minimum of Hurst fractal index is 0.932 and 0.532 , respectively, indicating that the settlement deformation with time has characteristics of trend and randomness. The settlement deformation tends to be stable due to the gradually decreasing trend of deformation with time. Also, the Hurst fractal index of horizontal deformation in $\mathrm{CH} 1 \sim \mathrm{CH} 3, \mathrm{CH} 5 \sim \mathrm{CH} 7$, and $\mathrm{CH} 10 \sim \mathrm{CH} 12$ is between 0.638 and 0.994, as shown in Figures 9(d)-9(f), which implies that the horizontal deformation series has the same properties as the settlement deformation. The fluctuation reason for Hurst fractal index in $\mathrm{CH} 1 \sim \mathrm{CH} 4$ during the year 2009-2011 may be related to the first water storage.

The fractal analysis of deformation monitoring data series of VE1-20, $\mathrm{CH} 1 \sim \mathrm{CH} 7$, and $\mathrm{CH} 10 \sim \mathrm{CH} 12$ shows that the Hurst fractal index of deformation series is between 0.523 and 0.944 . The results imply that the development and change in deformation with time have characteristics of trend and randomness; that is, the deformation series has long-range correlation, strong trend, and certain continuity.

3.3.2. Fractal Law and Mechanics Analysis of Dam Deformation. As for the mechanical cause of dam deformation, settlement deformation in the downstream rockfill area is mainly composed of the compression from filling loading and the creep deformation from rockfill particles crushing. The deformation shows a linear increasing trend of deformation in downstream rockfill area during the construction period, displaying that deformation in the next moment is positively related to the previous incremental trend, but the increasing trend gradually reduces with the completion of filling and development of creep, which can be verified by the Hurst fractal index in the study above. The case study of the Pubugou dam shows that the influence of first water storage on the horizontal deformation in the downstream rockfill area is more obvious than that on the settlement deformation. The influence of water level fluctuation on the deformation in the water level variation area is greater, and its influence on the deformation in points near the core is greater than that far from the core. From the aspect of the Hurst fractal index, the index of deformation in the Pubugou dam is convergent, and it is less than 1.0 during the construction and water storage period. Besides, the Hurst fractal index decreases gradually during the operation period; namely, the fractal dimension increases gradually, implying that the deformation in the downstream rockfill area tends to be stable as a whole.

The deformation of a core rockfill dam is an open system produced by the comprehensive action of multiple certainty and uncertainty factors. The analysis of deformation series in the Pubugou core rockfill dam shows that the Hurst fractal index reflects the influence of the current deformation of the 


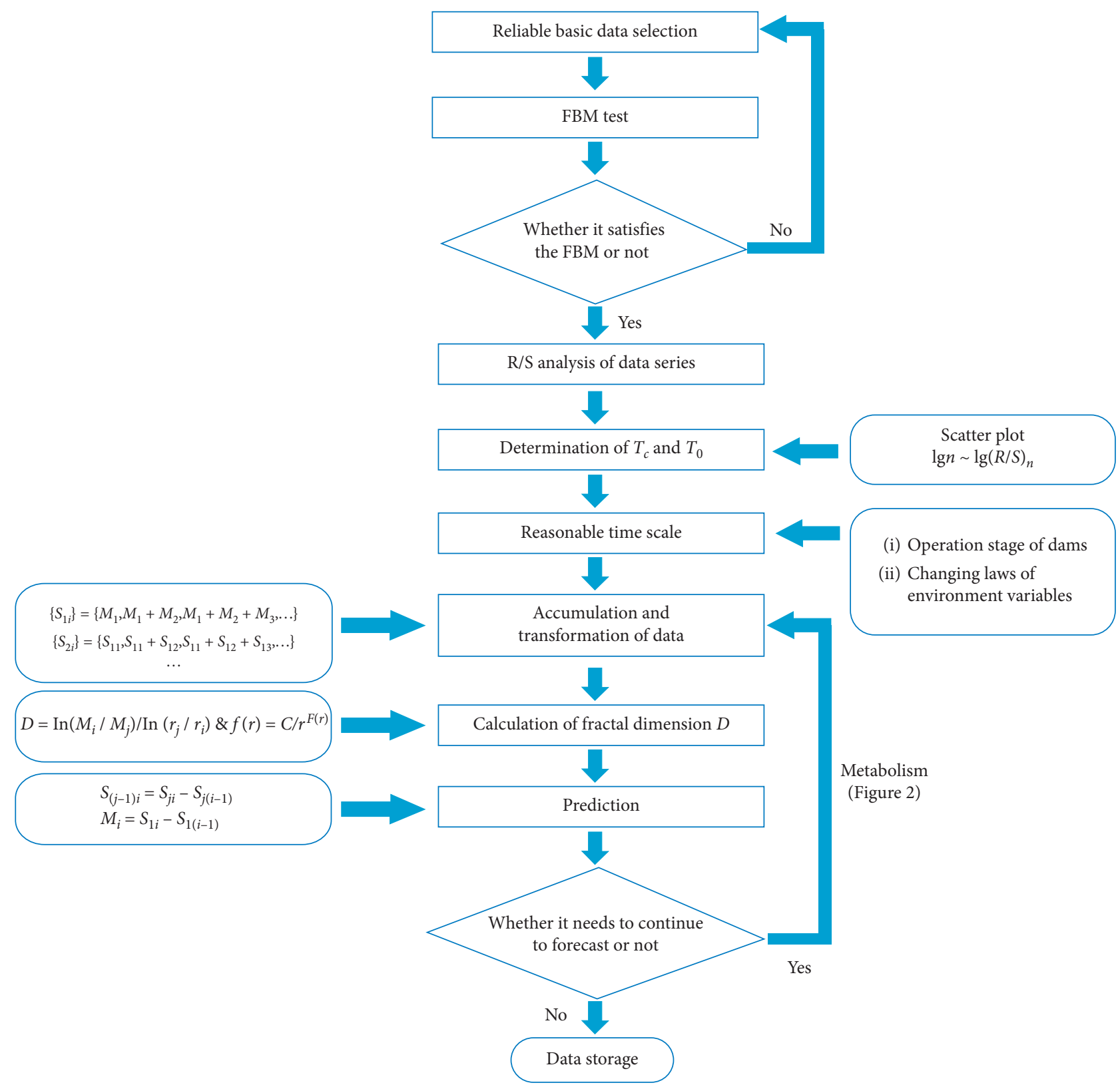

Figure 3: The flow chart of the proposed method in the paper.

dam on the future deformation (or previous deformation) and can be adapted to evaluate the system certainty and trend degree of dam deformation series. Also, the application of the Hurst fractal index in the deformation series of the concrete dams and the landslides shows similar results $[9,31]$. In a word, when the Hurst fractal index is introduced to the analysis of deformation series in the core rockfill dams, the closer the Hurst fractal index is to 1.0, the stronger the tendency of deformation series is; the closer the Hurst fractal index is to 0.5 , the stronger the randomness of deformation series is.

3.4. Fractal Prediction of Deformation. Based on the promoted model for the prediction by the fractal method, the $T_{0}$ is determined when the length of the data series between the initial time and the $T_{0}$ is 10 . The reasonable time scale is 2 months during the initial operation period of the Pubugou dam, its prediction of deformation is made, and the comparative results of the horizontal deformation in $\mathrm{CH} 10$ and the settlement deformation in VE1-27 are shown in Figures 10 and 11. The application shows that the value of fractal prediction is consistent with the actual value under the condition of periodic updating of data. As seen in Figures 10 and 11, the relative error between the predicted value and the actual value is within $3.71 \%$ during the period with a relatively stable deformation trend. The prediction accuracy decreases slightly, and the maximum relative error of individual points is $6.69 \%$ in the time that the deformation trend is about to change (in point VE1-27). 


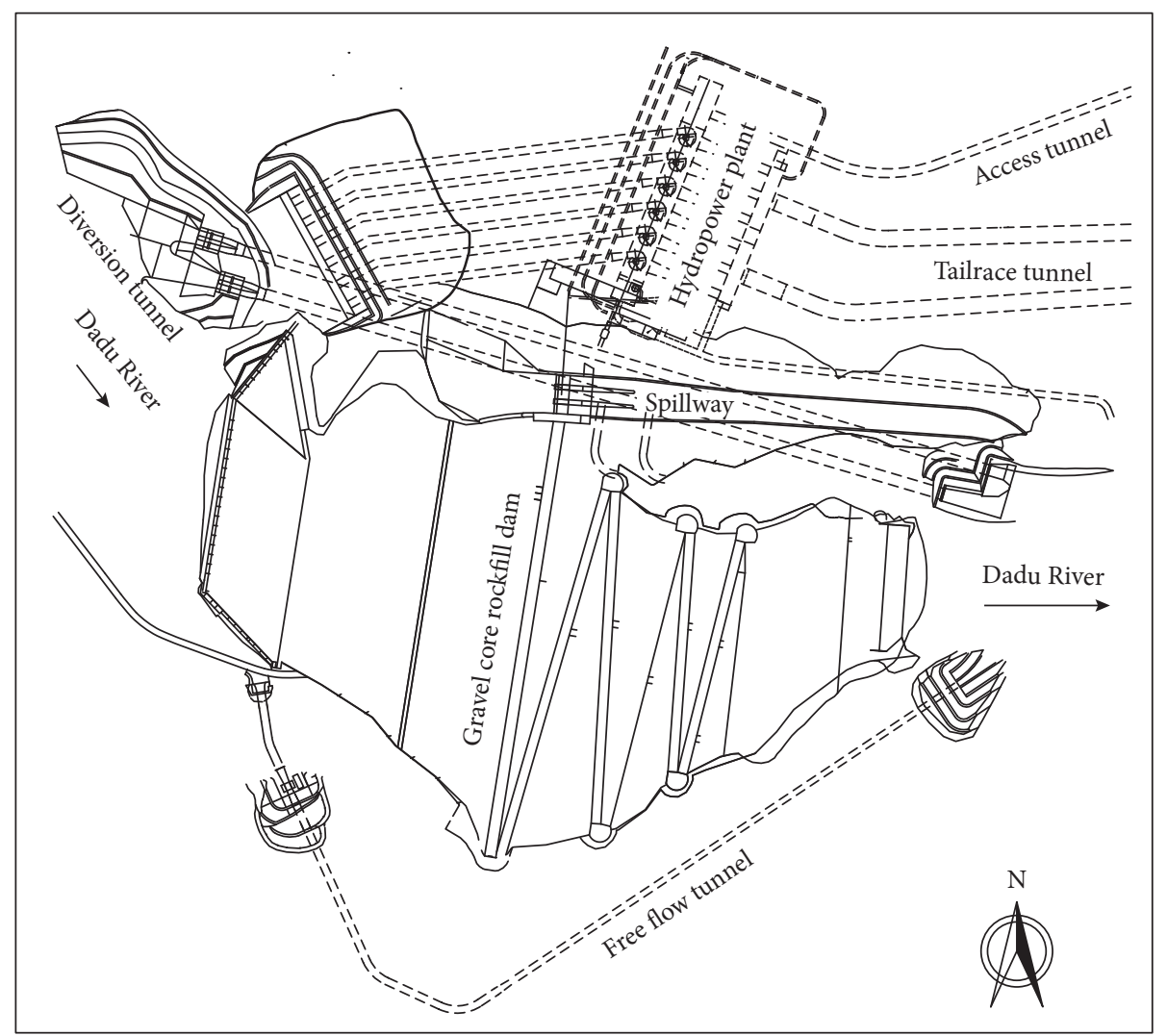

Figure 4: Layout of the Pubugou core rockfill dam.

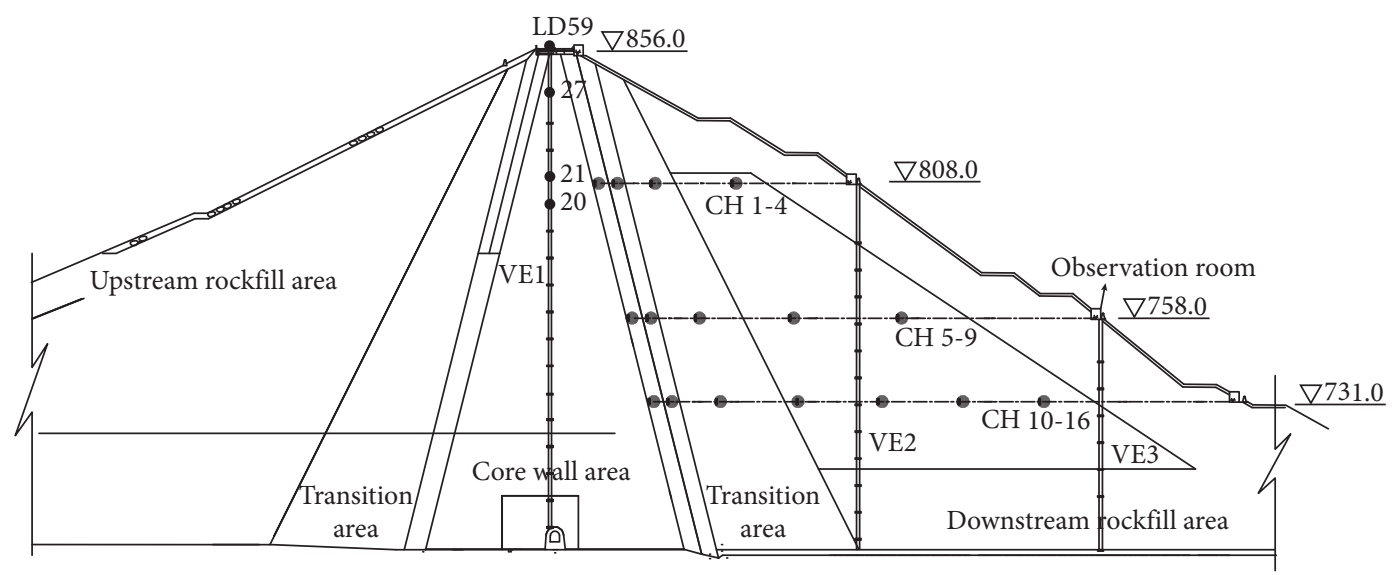

FIgURE 5: Layout of deformation monitoring points in section $0+240 \mathrm{~m}$.

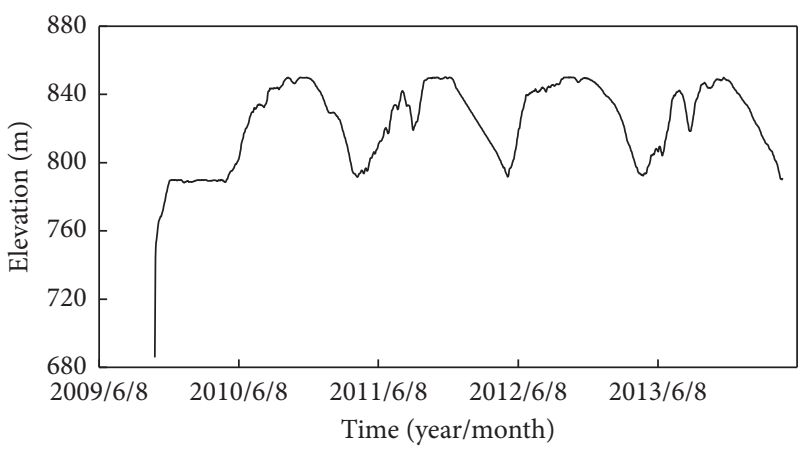

(a)

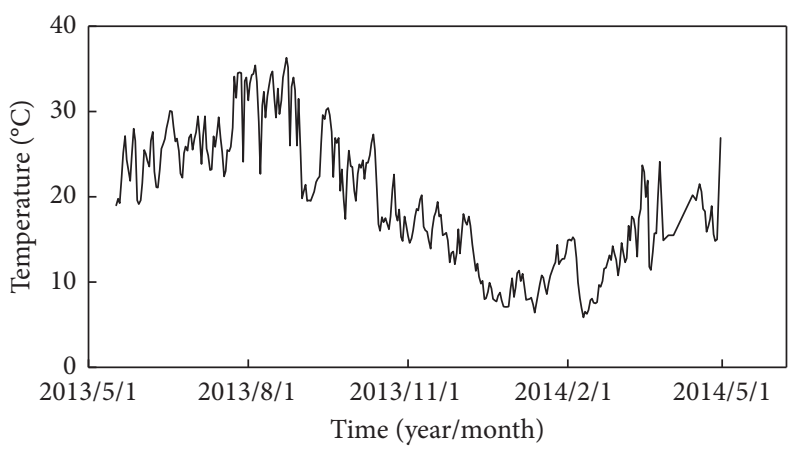

(b)

Figure 6: Environment variables in the Pubugou core rockfill dam: (a) water level; (b) temperature. 


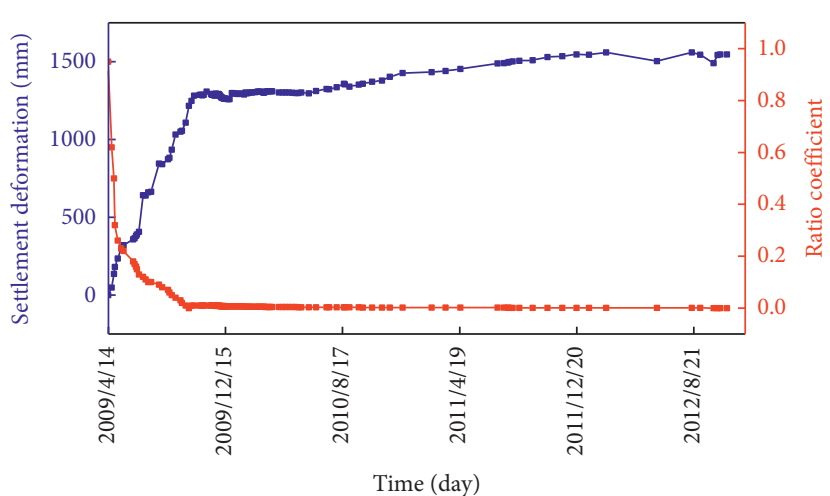

(a)

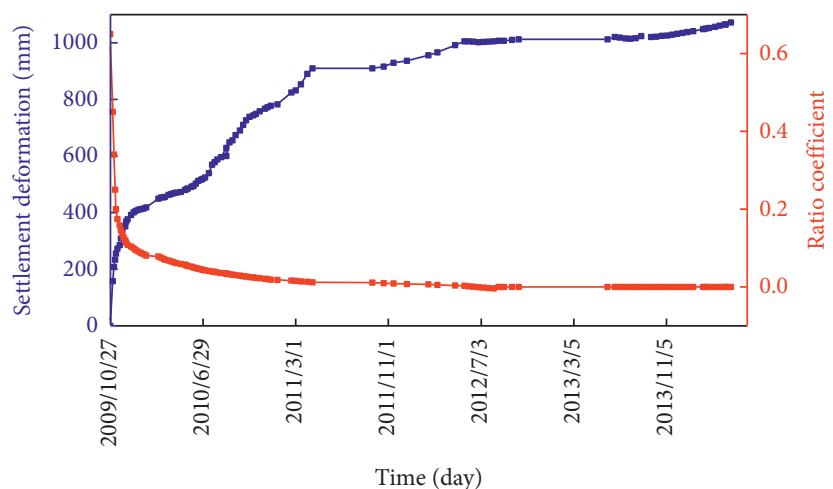

(c)

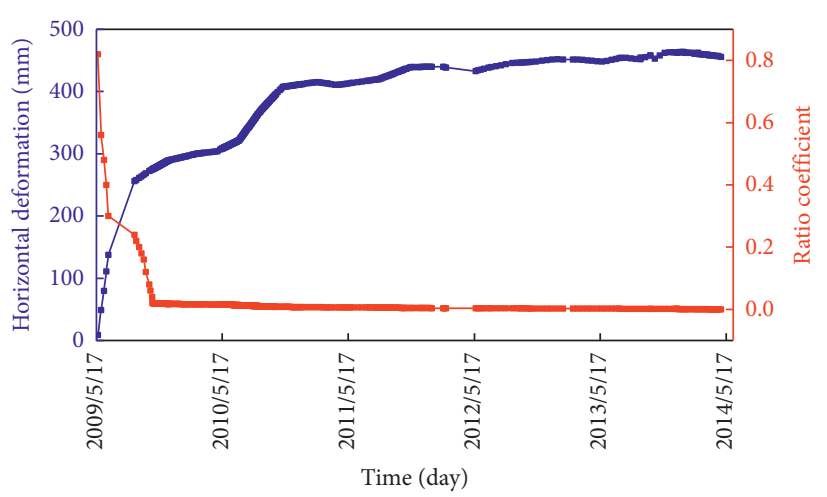

(b)

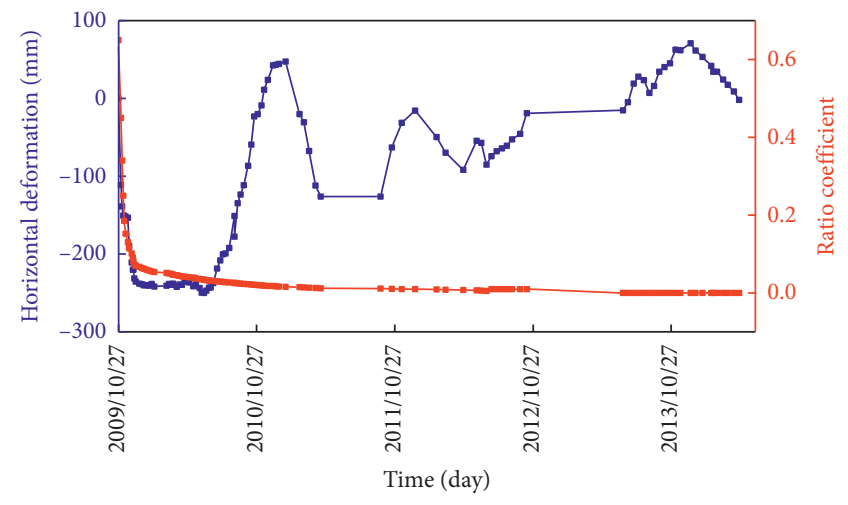

(d)

FIGURE 7: FBM test of deformation series in typical points: (a) settlement deformation of point VE1-21; (b) horizontal deformation of observation room in EL. 758 (m); (c) settlement deformation of point LD59; (d) horizontal deformation of point LD59.

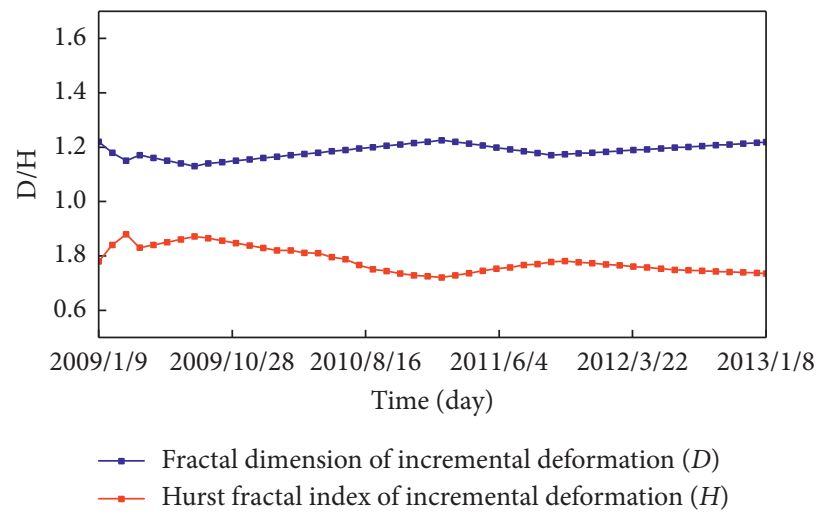

Figure 8: Hurst fractal index and fractal dimension of deformation series with time (VE1-20).

Traditional models, such as the stepwise regression, neural network, and time series model $[6,32]$, are widely used in the fields of deformation prediction in dams. To verify the accuracy of the prediction results, the stepwise regression method is introduced, and Table 2 shows the relative errors obtained by the proposed method and the stepwise regression method. As seen in Table 2, the proposed method has the advantage in aspects of the max and average value of relative errors over the traditional stepwise regression method, indicating that the proposed method provides a new and high accuracy way for the prediction of deformation in the dams.

The results illustrate that the prediction method of variable dimension fractal combined with data "metabolism" is 

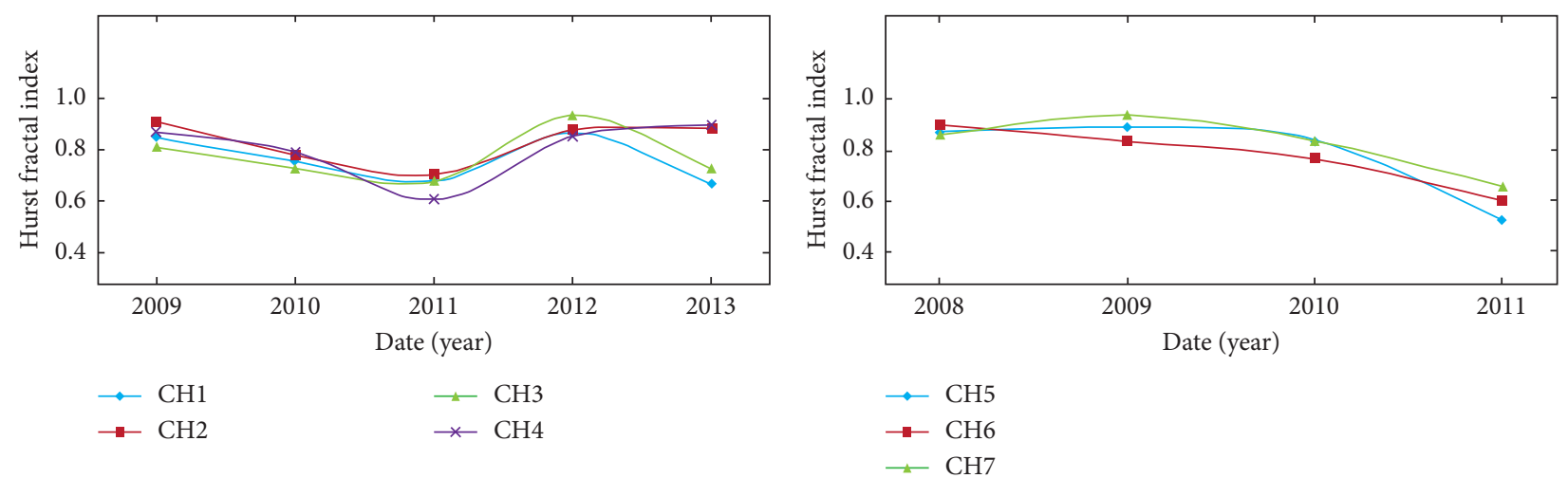

(a)
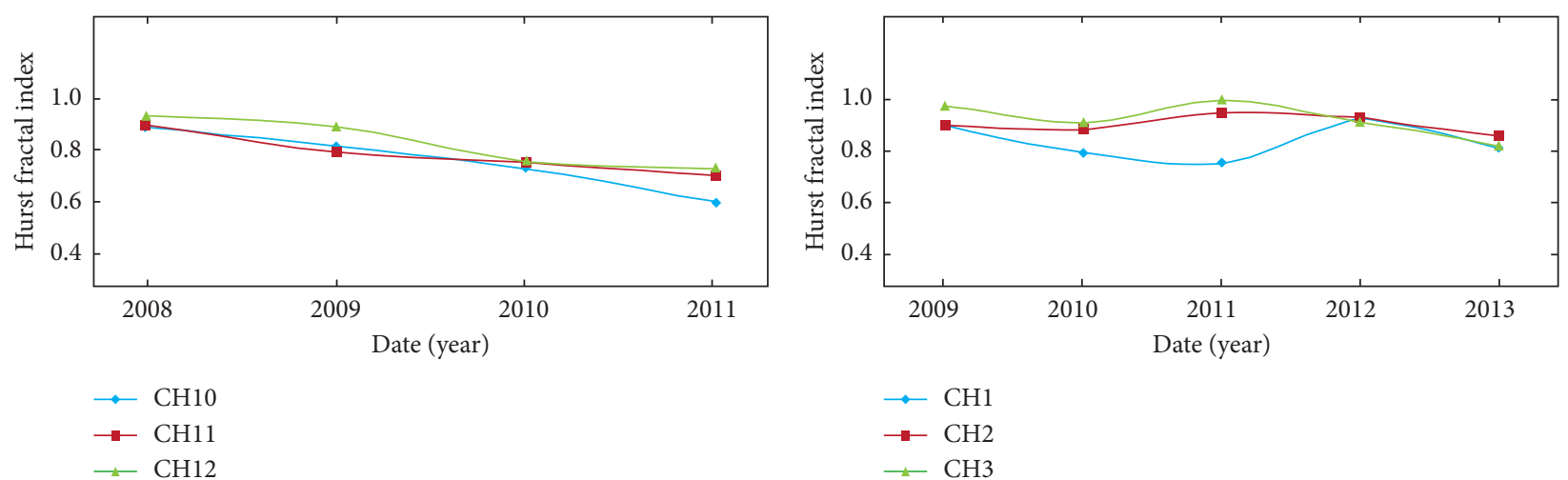

(c)

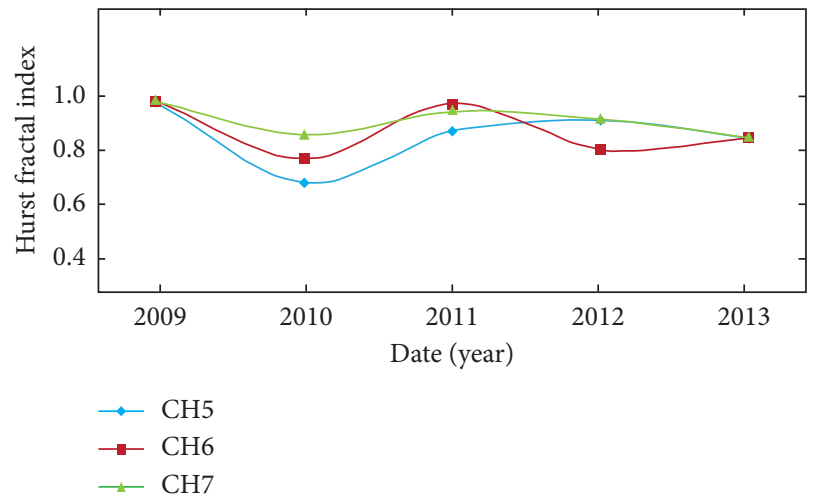

(e)

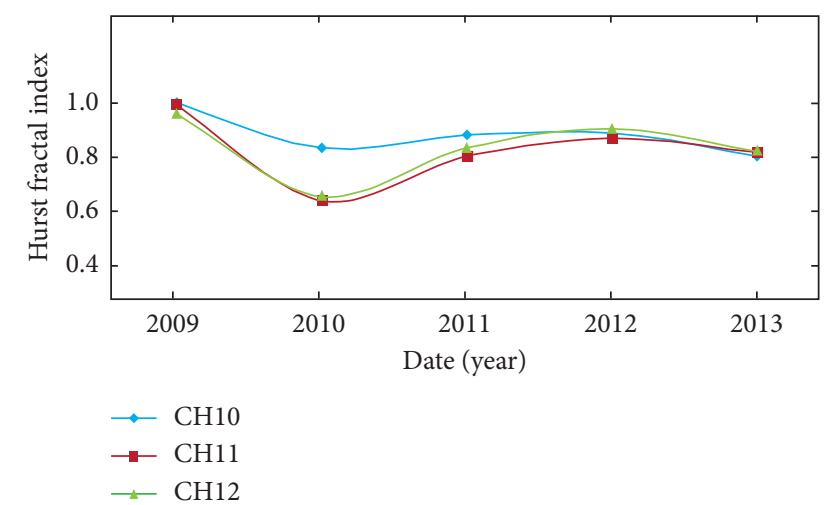

(f)

FIGURE 9: Hurst fractal index of deformation in different monitoring points: (a) Hurst fractal index of settlement deformation in CH1 CH4; (b) Hurst fractal index of settlement deformation in $\mathrm{CH} 5 \sim \mathrm{CH} 7$; (c) Hurst fractal index of settlement deformation in $\mathrm{CH} 10 \sim \mathrm{CH} 12$; (d) Hurst fractal index of horizontal deformation in $\mathrm{CH} 1 \sim \mathrm{CH} 3$; (e) Hurst fractal index of horizontal deformation in $\mathrm{CH} 5 \sim \mathrm{CH}$; (f) Hurst fractal index of horizontal deformation in $\mathrm{CH} 10 \sim \mathrm{CH} 12$.

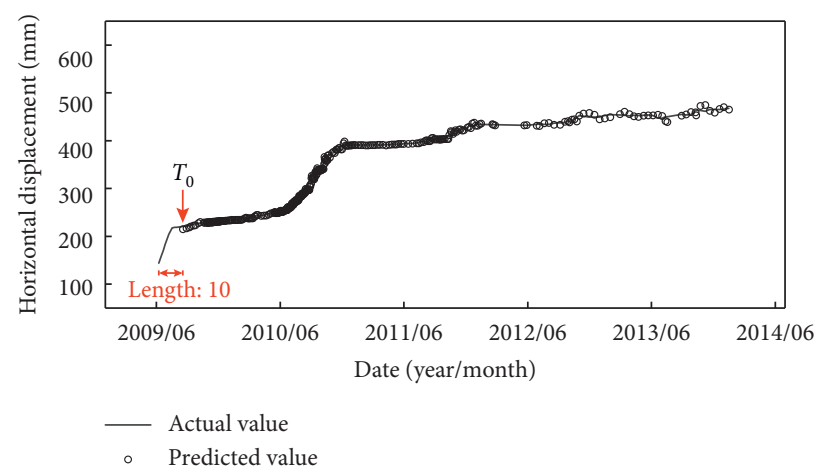

FIGURE 10: Prediction results of the horizontal deformation in monitoring point $\mathrm{CH} 10$. 


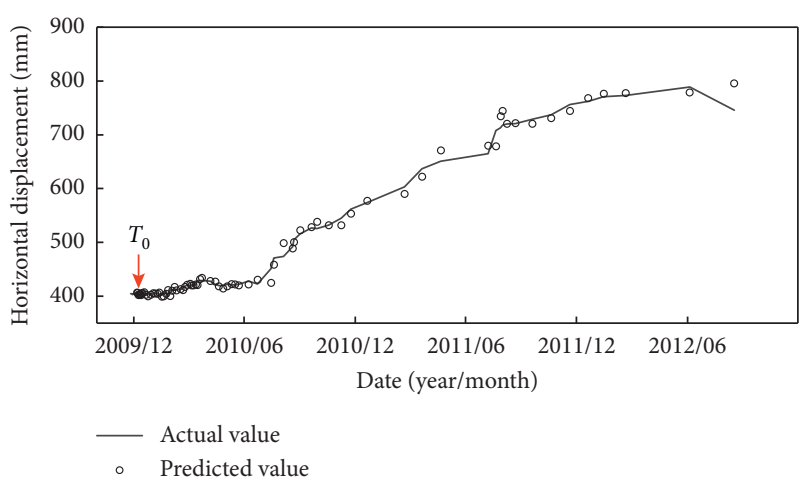

Figure 11: Prediction results of the settlement deformation in monitoring point VE1-27.

TABLE 2: Relative errors of the proposed method and the stepwise regression method.

\begin{tabular}{lcccc}
\hline \multirow{2}{*}{ Points } & \multirow{2}{*}{ Methods } & \multicolumn{3}{c}{ Relative error } \\
& & Max. (\%) & Min. (\%) & Aver. (\%) \\
\hline \multirow{2}{*}{ VE1-27 } & The proposed method & 6.69 & 0.00 & 1.19 \\
& Stepwise regression & 15.09 & 0.01 & 3.87 \\
\multirow{2}{*}{ CH10 } & The proposed method & 3.71 & 0.00 & 0.53 \\
& Stepwise regression & 14.74 & 0.00 & 3.00 \\
\hline
\end{tabular}

effective in dam deformation prediction and can be applied to well realize the dynamic prediction of deformation in dams.

\section{Conclusions}

In this paper, through the study of the improved fractal prediction method, analysis process, and engineering analysis of deformation series in core rockfill dam, the conclusions are as follows:

(1) A prediction method of variable dimension fractal combined with data "metabolism" for the deformation in the core rockfill dams is proposed in the paper. It effectively solves the decrease in prediction accuracy caused by the errors in the process of constant dimension fractal accumulation and transformation in dam deformation prediction based on the real-time update of basic data, thereby realizing the dynamic prediction of dam deformation and providing a new way for dam safety monitoring deformation prediction and early warning.

(2) Aiming at the characteristics of long-range correlation of dam deformation monitoring data series, a threshold time $T_{c}$ is used to describe the limit of long-range correlation limit. Based on the deformation prediction made by the known deformation data within the threshold time, the key technical process of variable dimension fractal prediction of deformation series in core rockfill dam is proposed.

(3) The trend and prediction analysis of deformation series in the Pubugou core rockfill dam shows that the fractal information of dam deformation has a good corresponding relationship with its physical causes, which is in line with the actual deformation trend and operation state of the dam. Compared with the traditional stepwise regression method, the prediction results obtained by the proposed method in this paper are of high accuracy.

\section{Data Availability}

Requests for access to the data of the dam should be made to Liang Pei. The calculated data used to support the findings of this study are included within the article.

\section{Conflicts of Interest}

The authors declare that they have no conflicts of interest.

\section{Acknowledgments}

This research was supported by the National Key R\&D Program of China (Grant no. 2018YFC0407103).

\section{References}

[1] J. C. Gu, Y. M. Shu, and C. S. Shen, Engineering Experience and Innovation on Rockfill Dam, Electric Power Press, Beijing, China, 2004.

[2] T. Z. Tang, G. Y. Li, and Z. Q. Xu, "Statistic prediction models of settlement for earth-rock dam," Hydro-Science and Engineering, no. 3, pp. 29-34, 2001.

[3] P. X. Wang and W. J. Song, "Analysis on the measured settlement and prediction modeling of statistic settlement of Shuibuya CFRD," Journal of Hydrologic Engineering, vol. 28, no. 4, pp. 81-85+101, 2009.

[4] J. S. Jiang and Z. K. Li, "Application of improved genetic algorithms in earth-rock dam settlement forecasting," Journal of Zhengzhou University Engineering Science, vol. 25, no. 4, pp. 74-77, 2004.

[5] Y. Shen, J. Y. Guo, J. Zhou, and H. J. Yu, "Subsidence prediction of earth and rockfill dam based on gray model and its improved models," Journal of Shandong University of Technology, vol. 28, no. 1, pp. 4-9, 2014.

[6] M. Li and J. Wang, "An empirical comparison of multiple linear regression and artificial neural network for concrete dam deformation modelling," Mathematical Problems in Engineering, vol. 2019, Article ID 7620973, 13 pages, 2019.

[7] Y. Chen, C. Gu, C. Shao et al., "An approach using adaptive weighted least squares support vector machines coupled with modified ant lion optimizer for dam deformation prediction," Mathematical Problems in Engineering, vol. 2020, Article ID 9434065, 23 pages, 2020.

[8] J. Zhang, X. Cao, J. Xie, and P. Kou, "An improved long shortterm memory model for dam displacement prediction," Mathematical Problems in Engineering, vol. 2019, Article ID 6792189, 14 pages, 2019.

[9] D. Lai, Z. Wu, and H. Zhou, "Application of fractal theory to analyze dam safety monitoring data," Shuili Xuebao, no. 1, pp. 100-104, 2004.

[10] X. P. He, X. S. Hua, X. F. He, Z. Y. Zhao, and Q. Zou, “The deformation partition on the collapsed accumulation body by fractal theory," Journal of China Coal Society, vol. 32, no. 7, pp. 691-694, 2007.

[11] Y. Wang, H. Jing, Q. Zhang, N. Luo, and X. Yin, "Prediction of collapse scope of deep-buried tunnels using pressure arch 
theory," Mathematical Problems in Engineering, vol. 2016, Article ID 2628174, 10 pages, 2016.

[12] Z. W. Bi, Z. J. Zhang, and D. X. Ding, "Application of FNN to mining subsidence prediction," Nonferrous Metals, vol. 56, no. 2, pp. 100-103, 2004.

[13] H. Su, Z. Wen, F. Wang, B. Wei, and J. Hu, "Multifractal scaling behavior analysis for existing dams," Expert Systems with Applications, vol. 40, no. 12, pp. 4922-4933, 2013.

[14] H. Su, J. Chen, Z. P. Wen, and F. Wang, "Wavelet-fractal diagnosis model and its criterion for concrete dam crack status," Transactions of the Institute of Measurement and Control, vol. 40, no. 3, p. 014233121769307, 2017.

[15] Y. Zhang, Y. R. Liu, Z. F. Tao, and H. W. Zhou, "Fractal characteristics and failure analysis of geomechanical model for arch dam based on acoustic emission technique," International Journal of Geomechanics, vol. 19, no. 11, p. 04019119 , 2019.

[16] H. Wu, Y. Dong, W. Shi et al., "An improved fractal prediction model for forecasting mine slope deformation using GM (1, 1)," Structural Health Monitoring: An International Journal, vol. 14, no. 5, pp. 502-512, 2015.

[17] X. M. Hu, E. C. Yan, K. Lv, and T. T. Zhang, "Fractal characteristics of motion trace curve of landslide monitoring points," Applied Mechanics \& Materials, vol. 90, pp. 93+1285-1290, 2011.

[18] J. W. Yang, E. F. Zhao, H. Wang, B. Wei, and J. Hu, "Analysis of dam crack state based on multifractal," Water Resources and Power, vol. 33, no. 5, pp. 55-58, 2015.

[19] L. Tu, T. Bao, Y. Li, and B. Zhao, "Arima dam early warning model based on fractal interpolation," Journal of china Three Gorges University (natural Sciences), vol. 37, no. 1, pp. 29-32, 2015.

[20] Z. Yan, L. Xu, Z. Shen, and Y. Sun, "Monitoring data analysis and behavior assessment of arch dam deformation based on R/S method," Water Resources and Power, vol. 33, no. 10, pp. 54-57, 2015.

[21] Y. Y. Li, K. L. Yin, and W. M. Cheng, "Application of R/S method in forecast of landslide deformation trend," Chin J of Geotec Engine, vol. 32, no. 8, pp. 1291-1296, 2010.

[22] S. R. Zhang, Q. C. Han, Y. S. Tan, and W. Q. Sa, "An R/S method-based study on settlement regularity and warning standard of earth-rock dam during construction," China Safe Sci Jour, vol. 22, no. 8, pp. 164-170, 2012.

[23] Y. Fu and Z. Liu, "Analytic method and application about Chaotic slope deformation destruction time-series," Journal of Wuhan University of Technology, vol. 27, no. 4, pp. 473-476, 2003.

[24] X. Xu, L. Ma, and Y. Chen, "Theoretical basis of R/S analysis: fractional brownian motion," Journal of Wuhan University of Technology, vol. 50, no. 5, pp. 547-550, 2004.

[25] B. B. Mandelbrot, C. J. G. Evertsz, and P. W. Jones, Fractals and Chaos: The Mandelrot Set and beyond, Springer, Berlin, Germany, 2004.

[26] H. Zhang, W. Wei, and S. Xue, "Analysis on the variation of temperature and precipitation in Dingxi based on R/S and Mann-Kendall test," Research of Soil and Water Conservation, vol. 22, no. 6, pp. 183-189, 2015.

[27] H. P. Xie and X. Q. Xue, The Mathematical Foundation and Method on Fractal Application, Science Press, Beijing, China, 1998.

[28] D. F. Yang and Y. Chen, Application and Research of Mathematical Model in Ecology, Ocean Press, Beijing, China, 2011.
[29] H. P. Xie, Fractals-rock Mechanics Introduction, pp. 239-243, Science Press, Beijing, China, 1996.

[30] H. Qiu, Z. Huang, and J. Zheng, "Research on time series analysis and prediction based on fractal principle," Journal of Southeast University (Natural Science Edition), vol. 23, no. S2, pp. 334-337, 2013.

[31] X. Xu, Y. Shang, and Y. Wang, "Fractal prediction of landslide control effect," Journal of Water Conservancy, vol. 42, no. 4, pp. 440-447, 2011.

[32] F. Kang, J. Liu, J. Li, and S. Li, "Concrete dam deformation prediction model for health monitoring based on extreme learning machine," Structural Control and Health Monitoring, vol. 24, no. 10, p. e1997, 2017. 